\title{
Embedded discourse spaces in narrative reports
}

\section{Discourse Studies 2020, Vol. 22(2) 22I-240 \\ (C) The Author(s) 2019 \\ Article reuse guidelines: sagepub.com/journals-permissions DOI: 10.1 | 177/| 46 |4456/9893776 journals.sagepub.com/home/dis \\ @SAGE}

\section{Anna Ewa Wieczorek}

University of Lodz, Poland

\begin{abstract}
This article aims to discuss conceptual levels of narrative representations of utterances based on reported speech frames employed in presidential speeches. It adopts some assumptions from Chilton's Deictic Space Theory and Cap's Proximisation Theory, both primarily used to indicate exclusive reference, a clash of interests and threat-oriented conceptualisation of events. This article, however, extends their scope to include strategies for inclusion and positive image construction and makes a distinction between primary, secondary and tertiary embedding as discursive means that contribute to presentation of self and legitimisation. Data for this research comprise a corpus of I 25 presidential speeches ( 25 per tenure) divided into three subcorpora: JKC - John Kennedy Corpus, BCC - Bill Clinton Corpus, and BOC - Barrack Obama Corpus. A total of $125 \mathrm{I}$ instances of narrative reports have been analysed to investigate primary and multilevel embedding, which constitute the basis for this study.
\end{abstract}

\section{Keywords}

Deictic centre, discourse analysis, discourse space theory, embedding, image construction, inclusion, legitimisation, narrative analysis, narrative reports, political discourse, presidential speeches, proximisation theory, reported speech frames, sayer, short narratives, storytelling

\section{Introduction}

Like any other form of communication, many a time, political speeches involve narrative elements, such as personal accounts of events, anecdotes or short stories to support and legitimise arguments the speaker is making. Bruner (1991) claims that people in general have an inborn inclination to 'organize experience and [...] memory of human

\section{Corresponding author:}

Anna Ewa Wieczorek, Department of Pragmatics, Institute of English Studies, University of Lodz, Pomorska 17I/I73, 90-236 Lodz, Poland.

Emails: anna.wieczorek@uni.lodz.pl; aewww@yahoo.com 
happenings [. . .] in the form of narrative' (p. 4) and Abbott (2008) describes narrative as present 'in almost all human discourse [and places it] next to language itself as the distinctive human trait' (p. 1). It is the latter's definition of the concept of narrative that is adopted in this research: a narrative constitutes a 'representation of an event or a series of events' (Abbott, 2008: 13). In his considerations, Abbott (2008) distinguishes between mere descriptions, as in 'My dog has fleas', and a narrative that reconstructs events, as in 'My dog was bitten by a flea' (p. 13). Narratives are therefore defined very broadly, in terms of past, present, future and imagined stories that involve a plot, sometimes relatively simple, a set of characters and their spatio-temporal conceptual locations in a story world (see Bal, 2009).

When narratives are incorporated into larger texts, events represented are re-contextualised in the current interactional setting, and make direct or indirect references to the context in which they occurred originally. Not only does this tendency shape in-group relationships, primarily by reducing conceptual distance between the speaker and the addressees, but also it contributes to eventual acceptance of his claims. Hodges (2011) suggests that narratives become socially meaningful, as they 'do not intrinsically contain their own interpretation [and it is] through language [that] such events [are] turned into a full account of experience' (p. 3), for example, by providing details about characters involved and contextual information, such as clarification and rationale behind their actions. Narratives are shared socially via 'language - and more specifically [via] discourse [and they do] not simply reflect events with meaning, [but] establish widespread social understandings and constitute social reality' (Hodges, 2011: 5).

This article aims to investigate the potential narrative reports have in constructing an image of self as the leader, on one hand, and as a group member, on the other. The literature investigating narrative genres proliferates with various approaches to the concept of narrative reports (Abbott, 2008; Bal, 2009; Fauconnier, 1985; Halliday, 1981, 1985; Tannen, 1989, 2006; Vandelanotte, 2008, 2009), which in my research is viewed in a fairly general manner. Narrative reports are seen as constructs based on reported speech frames; thus, utterances may be rendered via direct reports, indirect reports or both of them simultaneously within the same reported clause. It relies on the assumption that 'reported speech frames recontextualise previously uttered words and reinforce the meaning given to those words in their prior context' (Hodges, 2011: 94).

This article concentrates on discussing various levels of embedding of distinct discourse spaces (DSs) or story/text worlds (see Fauconnier, 1985; Werth, 1999) one within another with a view to building vivid representations of events in discourse. The concept of DS has been discussed by a number of scholars (Fauconnier, 1985; Gavins, 2007; Halliday, 1981, 1985; Levinson, 1983; Tannen, 1989, 2006; Verschueren, 1999; Werth, 1999); however, this research adopts Chilton's (2004, 2005, 2010, 2014) and Cap's $(2006,2010,2013,2017)$ pragmatic-cognitive approach and their definitions, in which it is seen as anchorage for conceptualisation of incoming messages.

This research into narrative-report-based storytelling practices has led to the development of two taxonomies of (a) sayers, that is, original speakers of words reported and (b) representations in which they are employed. A detailed and systematic discussion of both taxonomies exceeds the scope of this article, as it primarily focuses on embedding one representation within another via sayer and representation types. I will, however, make 
references to relevant sayer and representation categories in the empirical sections of this article. A selection of salient extracts from the data collected, namely, American presidential speeches, will be provided and analysed in terms of strategic use of distinct representation levels in short narratives.

\section{Aims, methodology and data}

Narrative representations of utterances naturally serve as powerful vehicles for legitimisation and authorisation, primarily due to their intrinsic capacity to evoke emotional response in the audience, which hampers, at least to some extent, their ability to draw a clear line between subjective observations on the speaker's part and factual information conveyed. Such persuasive representations of events and actors involved present the addressees with a biased perspective on reality, offering them an insight into the speaker's or another actor's experiences. Also, they tend to trigger a range of affective states and feelings, such as bonding, sympathy, appreciation, trust, hope and association, which contribute to the speaker's attempts at image construction and legitimisation. This is especially true in the case of narrative reports incorporated into short narratives, which stems from the fact that normally ' $\mathrm{t}$ ] he literal truth of the report is not questioned [but rather] opinions expressed in one's absence seem to have an enhanced reality, the incontestable truth of the overheard' (Tannen, 1989: 105).

Narrative reports that have been investigated as part of this research rely on reported speech frames (Bauman, 1986; Clark and Gerrig, 1990; Irvine, 1996; Tannen, 1989, 2006) featured in presidential speeches. Many a time they tend to function as metacommentaries on events discursively reconstructed by the speaker. Irvine (1996) assumes reported speech frames leave room for the speaker ' $[\mathrm{t}] \mathrm{o}$ animate another's voice, [which provides] a marvellous opportunity to comment on it subtly' (p. 149). This is largely why narrative reports, used in primary and multilevel representations, are strategically selected for the purposes of image construction. Thus, this study has two major goals: first, it aims to investigate how embedded representations based on reported speech frames contribute to the construction of a positive image of self and legitimisation and, second, to advance an original categorisation of such embedded representations and comments on the types of sayers they employ. It stresses the speaker's dominant position over the sayer in the hierarchy of consciousnesses given voice in representations of events.

In this research, references are made to a number of studies into narrative genres (e.g. Abbott, 2008; Bal, 2009), however, it primarily advocates taking a pragma-cognitive perspective on the analysis of narrative reports in political discourse enriched by insights from narratology. Selected assumptions made by Chilton $(2004,2005,2010,2014)$ in his cognitive approach to Critical Discourse Analysis and Deictic Space Theory (DST) and Cap's (2006, 2010, 2013, 2017) Proximisation Theory (PT) have been adopted. Although both scholars applied their models of analysis to investigate language reflecting and enhancing clash, dissociation, prejudice and threat-inducing discourse, my research adopts their assumptions and extends the potential of DST and PT to include discursive construction of unity, association and speaker's positive image. These aspects will be illustrated on the basis of primary and multilevel (secondary and tertiary) embedding of 
DSs within the DS which is conceptually and referentially tied to the speaker (henceforth the FDS for Frame Discourse Space), as well as their role in constructing an image of self as the leader and a group member.

As for the data collected, narrative-report-driven embedded DSs will be discussed with reference to extracts from a corpus of 125 speeches delivered by John Kennedy, Bill Clinton and Barrack Obama, between 1961 and 2017. In all, 25 speeches per each presidential tenure have been selected, which comprise texts written for delivery rather than transcripts of public addresses which have been delivered in a form that may potentially diverge from the original. This stems from the fact that my research focuses on how the said speeches are designed and constructed to produce the effect of an improvised story or anecdote shared with the audience as if out of an impulse rather than as a pre-meditated step towards winning their support, approval and/or affection. The empirical part of this article consists of a text-linguistic qualitative and quantitative ${ }^{1}$ analysis of narrative reports incorporated into short narratives. For clarity, the corpus has been divided into three smaller subcorpora: JKC (John Kennedy Corpus), BCC (Bill Clinton Corpus) and BOC (Barrack Obama Corpus). These abbreviated forms will be used henceforth in the following sections of the article. The speeches collected amount to a total of over 370,500 words and contain 1251 instances of narrative reports that provide illustration for the taxonomy of embedded DSs discussed in this article.

\section{DSs in narrative reports}

As a concept, DSs have been investigated from both cognitive and linguistic perspectives, for instance, in Fauconnier (1985), who concentrates on mental spaces, also those based on reported speech, as well as in Gavins (2007) and Werth (1999), who investigated 'text worlds'. Importantly, Werth's (1999) refers to Fauconnier's (1994) mental spaces in his Text World Theory and his in-depth discussion of 'text-driven world' ( $\mathrm{p}$. 103) claiming that they rely on propositional content of utterances established by reference markers and deictic expressions. Levinson (2000) discusses DSs as part of his considerations on the nature of spatio-temporal reference frames along with a related concept of Deictic Centre (DC), which Verschueren (1999) treats as a conceptual point of reference constructed by speakers (to whom he refers to as 'utterers') and addressees ('interpreters') in the process of communicative interaction that anchors conceptualisation of events represented. Chilton and Cap provide an important insight from pragma-cognitive perspective into such discourse ontologies and compare them to Fauconnier's (1985) mental spaces, as well as Werth's (1999) text worlds and sub-worlds. Importantly, they both consider deictics to be means for 'induc[ing] interpreters to conceptualise group identity, coalitions, parties and the like, either as insiders or as outsiders' (Chilton, 2004: 56), groups which Cap (2006, 2010, 2013, 2017) refers to as IDCs (Inside-Deictic-Centre entities) and ODCs (Outside-Deictic-Centre entities). DC itself is a central notion to conceptualisation of DS in terms of spatial, temporal and axiological (STA) distance from its focal point, that is, the speaker (Cap, 2006, 2010, 2013, 2017). It is based on an assumption that 'discourse worlds require entities in it to be relativized to the self, the self is the speaker [or the sayer], but the speaker may [also] claim identity with the hearer and third parties' (Chilton, 2004: 204). In other words, the construction of identity is 
primarily executed via conceptual positioning of discourse entities, such as actors and events on STA axes (henceforth referred to as S-axis, T-axis and A-axis, respectively) that are conceptual representations of the three dimensions of the DC.

Several major assumptions made by Chilton and Cap have been adopted to propose a model for analysis of narrative reports employed for image construction and legitimisation. In any DS, there are three major dimensions, namely: (a) spatial, which encodes physical (Chilton, 2004) and geopolitical distance and proximity (Cap, 2006) between discourse entities and is based on conceptualisation of discourse entities in terms of closeness and remoteness as well as in terms of centrality and peripherality (Chilton, 2004); (b) temporal, which encodes distance in time (Chilton, 2004), as well as projects the momentous and historic character of events represented (Cap, 2006, 2013) and (c) axiological, which encodes intra- and intergroup relations, ideology (Cap, 2006) as well as deontic and epistemic modality (Chilton, 2004). These assumptions have been adopted for the purpose of analysing textual features employed in order to construct image of self via association-inducing strategic uses of narrative reports based on reported speech frames:

[1] I know I speak for everyone in this chamber, Republicans and Democrats, when I say to Saddam Hussein, 'You cannot defy the will of the world'. ${ }^{2}$ (BCC 27 January 1998)

In the reporting clause in extract [1], the speaker is pictured as the leader of a nation (I say), whose actions are legitimised via reference to an ODC entity. On behalf of American citizens, he communicates common stance held by IDCs against a specified ODC actor, whose conceptual location on the A-axis places him outside the DC, as seen in the visual representation (Figure 1):

When plotted, the spatial coordinate (this chamber), the temporal coordinate indexed via present tense (in verbs say and speak), as well as axiological coordinates (Democrats and Republicans) indicate conceptual location of everybody in the DC, that is, addressees categorised as IDCs irrespective of their political leanings. In this case, the speaker is referentially equivalent to the sayer, however, conceptually a distinct entity.

Chilton's DST assumes that conceptualisation of discourse per se relies on geometrical approach to meaning. In his model of a three-dimensional DS, the spatial dimension is dominant over the remaining two in the sense that they both rely on spatial conceptualisation. Time is seen as passing through space, and axiology enables positioning DS entities here and there epistemically, deontically and ideologically. The three dimensions are represented in terms of axes intersecting at the DC, which is positioned spatially 'here', temporally 'now', and axiologically as 'us', 'good' and 'right'. Importantly, the term 'positioned' is seen as 'a spatial metaphor conceptualising the speaker's [. . . ] relationship to their interlocutor(s), to their physical location, to the point in time of the ongoing utterance, and to where they are in the ongoing discourse' (Chilton, 2004: 56).

\section{Embedding DSs in narrative reports}

DST and PT both provide a valuable insight into the functions of linguistic deixis and deixis-driven expressions that constitute coordinates positioning discourse entities along the three STA axes in the DS. Chilton (2004) claims " deictic expressions" are linguistic 


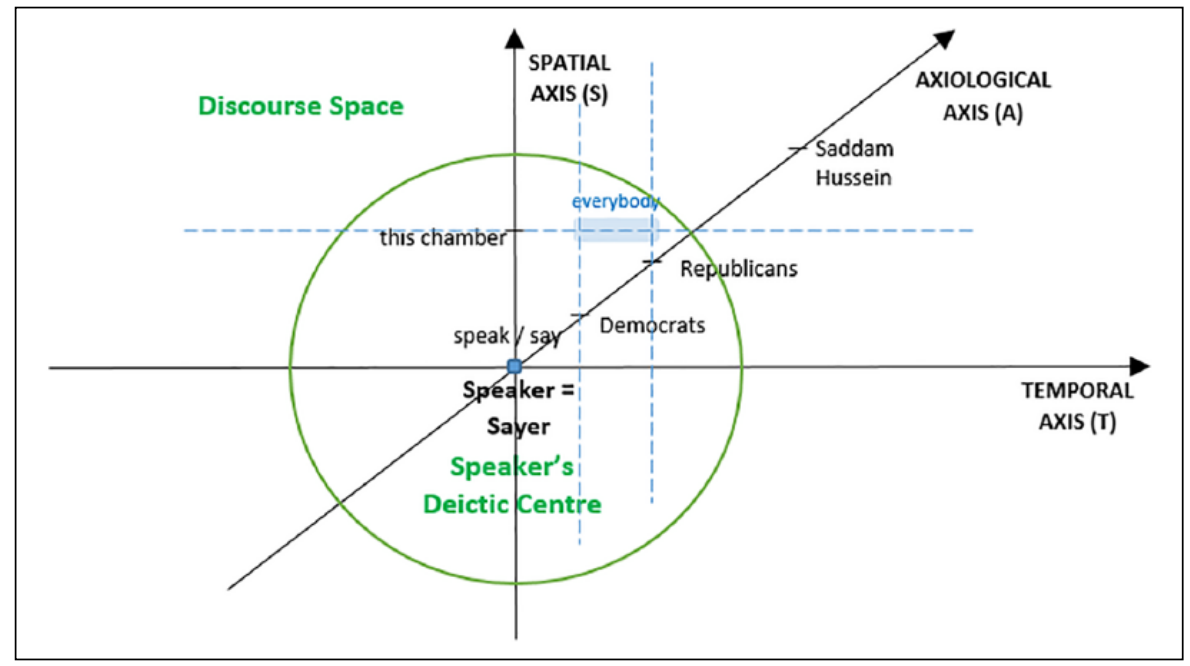

Figure I. Visual representation of the speaker's FDS, extract [I].

resources used to [. . .] prompt the interpreter to relate the uttered indexical expression to various situational features' (p. 56). In the words of Cap (2017), 'the ontological status and pragmatic function of deixis and deictic markers is revisited at the cognitive-pragmatic conceptual level' (p. 17) in PT. Traditionally (Fillmore, 1975; Frege, 1967 [1892]; Levelt, 1989; Levinson, 1983, 2000; Lyons, 1982; Nunberg, 1998), deictics are seen in terms of integral components whose function was reduced to formal aspects in the process of encoding and interpreting language in communication. However, its scope within the frameworks of DST and PT is seen as far wider:

[i]t is potentially an instrument [. . . ] for legitimisation, persuasion and social coercion, [which means] the concept of deixis is [. . .] expanded to include bigger lexico-grammatical phrases and discourse expressions in which conventional deictic markers (e.g. pronominals) partake to force conceptual operations. (Cap, 2017: 18)

These operations involve image creation and legitimisation executed via conceptual closeness indicated in the three dimensions of the DS. Thus, chunks of language that often involve the use of deictics index contextual as well as pragmatic information on spatio-temporal, socio-political and ideological context of messages conveyed:

[2] A few weeks ago, I was privileged to spend some time with His Holiness, Pope John Paul II, when he came to America. At the very end of our meeting, the Pope looked at me and said, 'I have lived through most of this century. I remember that it began with a war in Sarajevo. Mr. President, you must not let it end with a war in Sarajevo'. (BCC 27 November 1995)

There are clearly two sets of coordinates in DSs tied to the speaker and the sayer positioning events represented by them, respectively, within or out of their DCs (marked as ODC in Table 1): 
Table I. STA coordinates in the speaker's and the sayer's DSs, extract [2].

\begin{tabular}{|c|c|c|}
\hline & Coordinates for speaker's FDS & Coordinates for primary sayer's DS \\
\hline S-axis & America & in Sarajevo (ODC) \\
\hline \multirow[t]{3}{*}{ T-axis } & the end of (our meeting) & $\begin{array}{l}\text { perfect tense in have lived } \\
\text { present tense in remember }\end{array}$ \\
\hline & a few weeks ago & past tense in began \\
\hline & past tense in was, came, looked, said & \\
\hline \multirow[t]{4}{*}{ A-axis } & His Holiness, Pope John Paul II, the Pope & Mr President, you \\
\hline & I/me & 1 \\
\hline & our meeting & war (ODC) \\
\hline & & must not \\
\hline
\end{tabular}

STA: spatial, temporal and axiological; FDS: frame discourse space; DS: discourse space; ODC: OutsideDeictic-Centre entities.

The opposition between the ODCs and IDCs here highlights association in the DC, adding to the overall sense of togetherness. These coordinates indicate conceptual locations of events and actors involved classifying them as IDCs and ODCs, entities that are either close or remote from the speaker spatially, temporally and axiologically. By reporting on a meeting with the Pope and thus associating himself with this public figure held in much esteem, the speaker builds up his positive image of a powerful leader. Moreover, he stresses the aura of unity and belonging indicating IDC entities: it is only through the sayer's DS that two ODC concepts (Sarajevo and war) are plotted outside both DCs. Thus, he promotes his association with the Pope and contrasts selected concepts in spatial (geographical - America and Sarajevo), temporal (implicitly past - a war in Sarajevo, and future - the second metonymic reference to a war in Sarajevo) and axiological (our meeting (peace) vs a war) dimensions.

Conceptual location of discourse entities both across various levels of embedding and within a single three-dimensional DS is fully dependent on STA coordinates, which comprise lexico-grammatical units, many of which are deixis-driven. Cap (2017) proposes a set of six categories of such units that constitute his proximisation framework (p. 19), which are adaptable for the purposes of this investigation. These include, for instance, noun phrases for IDC and ODC classification and verb phrases for representation of impact and movement towards the DC. Importantly, this study investigates movement into, in and out of the DC and involves conceptual switches from one DS to another. Thus, it calls for further research into the aforementioned and other lexical and grammatical markers of closeness and remoteness, such as adverbial and prepositional phrases, which exceeds the scope of this article. As for discourse entities conceptualised via DC coordinates, Werth (1999) finds what will be referred to here as actors to be salient elements in a representation. In his approach, they constitute integral elements that construct a text world and may constitute triggers for another embedded world, by which means an insight into their perspective is offered. This article will refer to such subworlds, in Werth's (1999: 55) terminology, as embedded discourse spaces with respective sayers as their focal points. The concept in question has also been discussed by Gavins (2007) under the name of world switches. Both Werth (1999) and Gavins (2007), 
however, do not concentrate on distinct levels of embedding from a pragmatic-cognitive point of view, which is of primary importance in this article. Here, embedded representations rely on a perspective taken on events represented discursively which is governed by deictics positioning events and actors according to specific STA coordinates, which, when plotted, pinpoint their conceptual location in the DS.

After DST and PT, this research relies on a number of significant considerations about DSs in general. First, entities represented discursively are conceptualised as 'positioned' in the DS along STA axes in relation to the speaker. Second, the speaker is located at the intersection of the axes representing DS's conceptual dimensions. Third, in representing and taking a specific perspective on events, the speaker relies on the common ground pre-established with the addressees. These bottom-line assumptions clearly indicate the FDS is the default anchorage for conceptualisation, in which further DSs may be nested.

This research distinguishes between primary and multilevel embedding: primary embedding refers to a situation in which the primary sayer's (PS) DS is nested within the speaker's FDS. Embedding another DS in the PS's DS, in turn, gives rise to a secondary representation with a secondary sayer (SS) as its focal point. This recursion-driven mechanism may in theory continue at infinitum; however, in the three subcorpora investigated, there are no further instances than tertiary embedding, probably due to the cognitive cost one would have to take to interpret messages nested within tertiary representations. The following extract is representative of such multilevel embedding. The FDS sets the narrated event in the current STA context tied to the speaker, which in this case provides support for his engagement and interest in the lives of American citizens:

[3] (a) Before he left for the mine on Monday, Josh wrote a letter for his girlfriend and young daughter. And in it, he said, (b) 'If anything happens to me, I'll be looking down from heaven at you all. I love you. Take care of my baby. Tell her that (c) daddy loves her, she's beautiful, she's funny'. (BOC 09 April 2010)

For clarity, the extract is divided into sections (a) to (c) to indicate each level of embedding, in which (a) refers to the speaker's anchorage, (b) to PS's and (c) to SS's DSs (Figure 2).

Contextual information that describes the STA dimensions of the event represented (Before he left for the mine on Monday, Josh wrote a letter for his girlfriend and young daughter. And in it [. . .]) and the reporting clause (he said) provide a set of coordinates interpretable in relation to the speaker's anchor point. Temporal coordinates provide information on the chronology of the events represented via time deictics before and Monday, as well as via past tense in left, wrote and said. Spatial coordinates are reflected in the use of the definite article in the Noun Phrase (NP) the mine, which indicates the audience might have prior, direct or contextual, knowledge of the place, which thus serves as a means of proximizing the event conceptually. The speaker positions Josh and other actors involved (his girlfriend and young daughter) inside the DC along the A-axis. When plotted with temporal markers on the T-axis, it indicates a past event of Josh's making an utterance, that is, writing the letter, in the reported clause. 


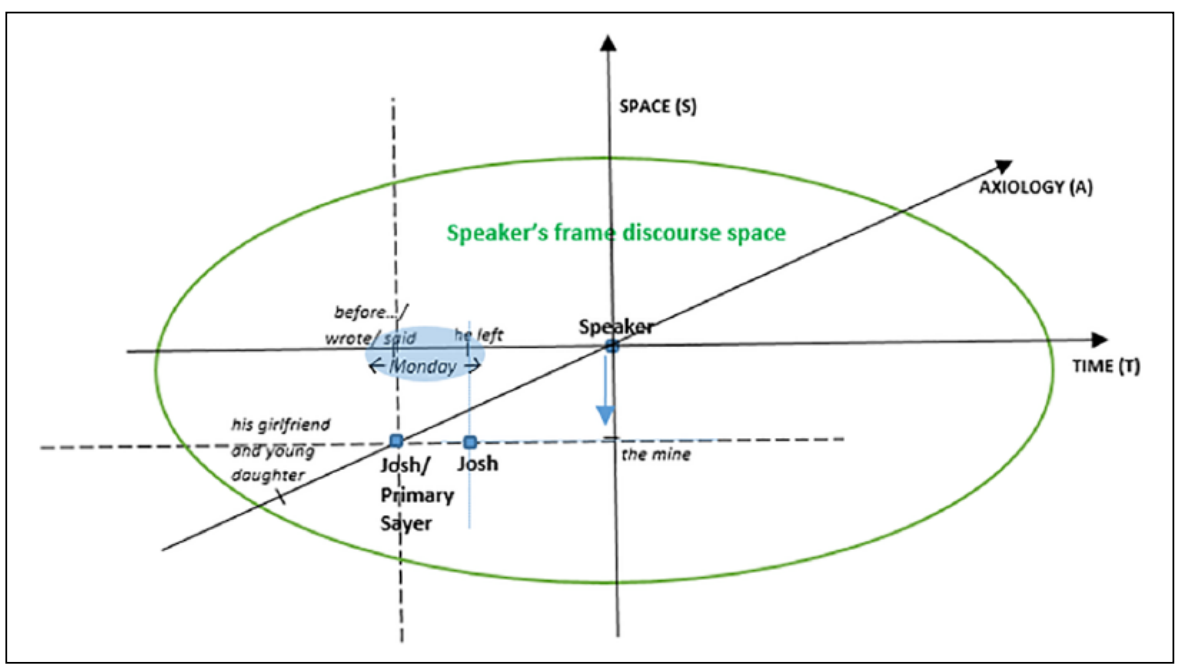

Figure 2. Visual representation of the speaker's FDS, extract [3], fragment (a).

Fragment (b) represents the use of another DS nested in the FDS. Direct speech frame used to set the PS's (Josh's) utterance in the speaker's FDS activates a fully operational DS within which it requires a full conceptual switch into this new perspective and serves as an independent anchorage for interpretation of coordinate expressions. Since direct reported speech frame is used, all reference markers are interpretable in relation to the PS's embedded DS (Figure 3).

The only ODC entity is the hypothetical future event (anything) plotted via an A coordinate and T coordinate (future in if . . . happens). By contrast, in the case of SS (Josh's partner represented from the PS's anchorage via personal deictic you), is non-operational (see fragment (c)). The representation is anchored in the PS's rather than SS's DS, which stems from the use of indirect reported speech frame in a single-anchorage representation. In such an instance, instead of a full switch, a conceptual shift occurs, indicating the existence of a sayer whose words are filtered through PS's perspective (Figure 4):

In this case, in the SS's utterance anchored in the PS's DS, a singular shift to yet another sayer's perspective occurs. The SS refers to the daughter's DC in which it is from her point of view that the deictic $d a d d y$ can be interpreted. Importantly, the SS's utterance in the extract in question is an instance of hypothetical representation, that is, a report on an utterance by the sayer which has never been made in the first place (as opposed to genuine representations, namely, words that have been uttered). The speaker pictures himself as the leader and as an individual emotionally bonded with other ingroup members. Such stories illustrating events addressees might have experienced themselves may greatly contribute to elicitation of an affective response in the audience, which, in turn, facilitates reception of the claims made by the speaker and evokes a sense of rapport and closeness.

There seems to be abundant evidence to claim both DST and PT are perfectly adaptable for the purpose of narrative analysis in political speeches, as they can account for the 


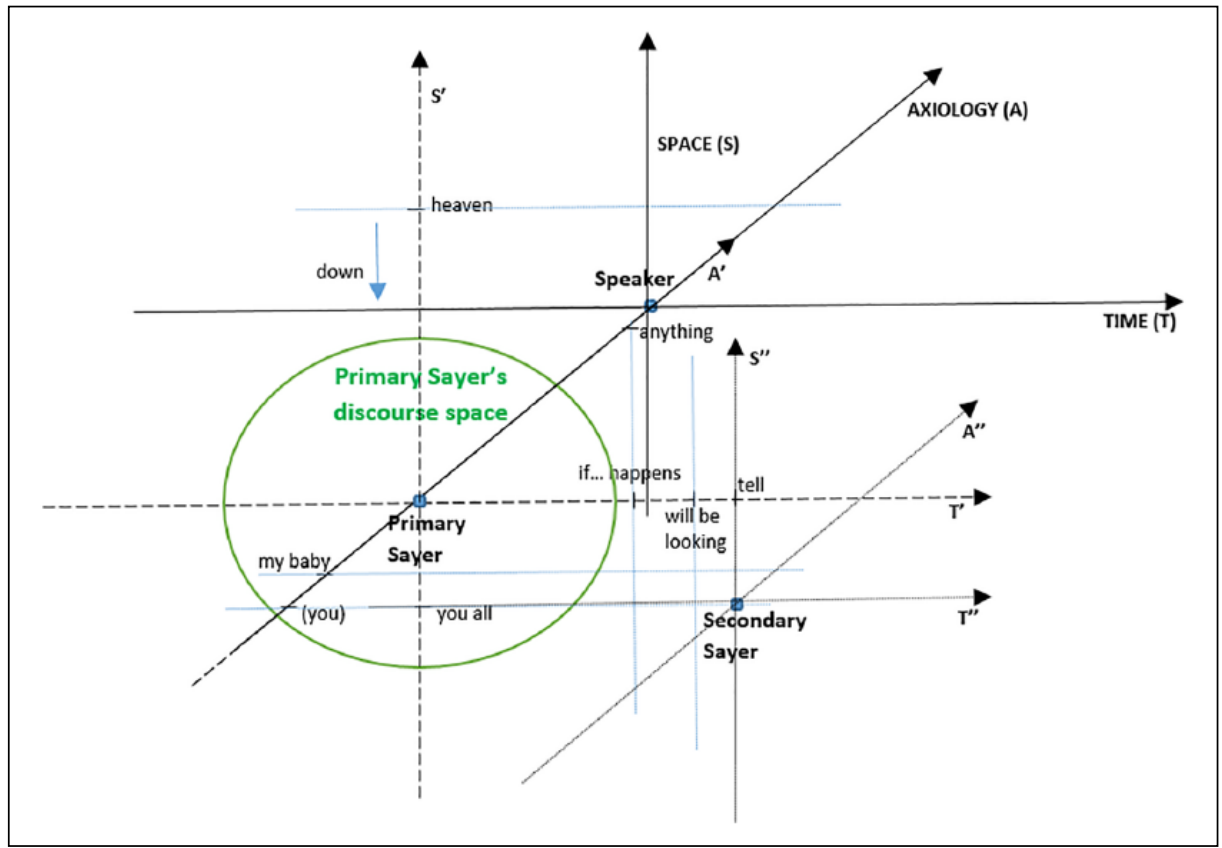

Figure 3. Visual representation of PS's DS, extract [3], fragment (b).

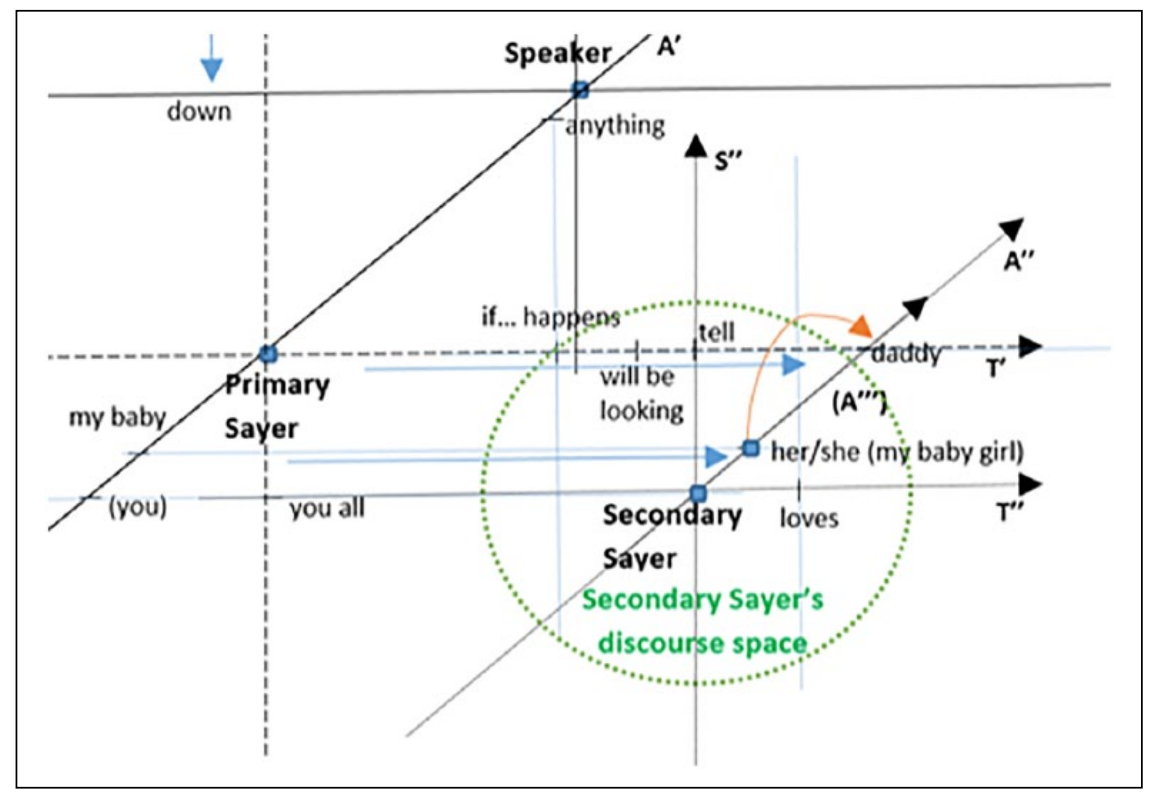

Figure 4. Visual representation of SS's DS, extract [3], fragment (c). 
Table 2. Occurrences of representation types in the corpus.

\begin{tabular}{llll}
\hline & Single-anchorage & Multi-anchorage & Mixed-anchorage \\
\hline JKC & $39 \%$ & $50 \%$ & $11 \%$ \\
BCC & $32 \%$ & $65 \%$ & $3 \%$ \\
BOC & $34 \%$ & $61 \%$ & $5 \%$ \\
\hline
\end{tabular}

JKC: John Kennedy Corpus; BCC: Bill Clinton Corpus; BOC: Barrack Obama Corpus.

Table 3. Occurrences of primary and multilevel representations in the corpus.

\begin{tabular}{|c|c|c|c|c|c|c|}
\hline & \multicolumn{2}{|c|}{ Single-anchorage } & \multicolumn{2}{|c|}{ Multi-anchorage } & \multicolumn{2}{|c|}{ Mixed-anchorage } \\
\hline & Primary & Multilevel & Primary & Multilevel & Primary & Multilevel \\
\hline $\mathrm{JKC}$ & $39 \%$ & - & $48 \%$ & $2 \%$ & $11 \%$ & - \\
\hline $\mathrm{BCC}$ & $31.5 \%$ & $0.5 \%$ & $63 \%$ & $2 \%$ & $2.5 \%$ & $0.5 \%$ \\
\hline $\mathrm{BOC}$ & $34 \%$ & - & $59 \%$ & $1.8 \%$ & $5 \%$ & $0.2 \%$ \\
\hline
\end{tabular}

JKC: John Kennedy Corpus; BCC: Bill Clinton Corpus; BOC: Barrack Obama Corpus.

use of multiple voices within the same or across distinct DSs, each with their respective focal figures and independent STA coordinate systems. Narrative reports are seen as relying on the speaker's dominant position over the consciousnesses who are given voice in a representation, and they are hierarchical in nature. As such, they serve to reveal distinct voices employed strategically by the speaker and relations between them in the discourse of politics at large. Data analysis indicates that all representation types, direct (multi-anchorage), indirect (single-anchorage) and mixed-anchorage, exhibit similar pattern of occurrence in all three subcorpora with direct being the most and mixed being the least frequent types (see Table 2). Slight differences in distribution stem from individual speaker's preferences exercised in speech texts.

Multi-anchorage narrative reports add vividness to a representation and support trustworthiness of the speaker's account of events, single-anchorage create the aura of an impartial report of what is rendered discursively, while mixed combine these qualities at a slightly higher cognitive cost to the addressees.

As for the primary and multilevel representations, the former clearly prevail (see Table 3). The latter, on the contrary, require switches to the sayer's DSs, possibly a number of times and to a various extent of embedding, which adds to the conceptual effort on the part of the addressees in their attempt to interpret referents in the incoming messages. This probably explains why primary representations constitute $97.6 \%$, secondary $2 \%$ and tertiary $0.4 \%$ of all embedded representations. Although this study has not been designed to compare and contrast the three subcorpora analysed, it is worth noting that they all represent a similar pattern of occurrences regarding distribution of primary and multiple embedding according to representation types (e.g. primary embedding amounts to $31.5 \%-39 \%$ in single-anchorage representations, $48 \%-63 \%$ in multi-anchorage representations, and $2.5 \%-11 \%$ in mixed-anchorage representations), which may be 
indicative of a tendency in presidential speeches aiming at legitimisation and image construction. This assumption, however, requires further research to confirm.

The following sub-sections aim to discuss primary and multilevel representations as means of fostering positive image of self and legitimisation of political stance and actions. They provide numerical data and qualitative analysis to indicate a tendency of use of narrative reports for the purposes specified above.

\section{Primary representations}

DSs embedded in the FDS reflect hierarchical relations between the current speaker and sayers, representations of whose utterances are controlled by the speaker in the sense that he (re-)sets them in a context which may and often does influence interpretation of their messages. The following examples constitute instances of the use of reported speech frames in the service of image construction and legitimisation, which will be taken into account here as representations of self as (a) an in-group member via discursive exploitation of his inclusive IDC status of a regular American citizen and (b) an in-group member via exploitation of his inclusive IDC status as the leader.

In the following extract, the speaker attempts to present himself in one of the roles he plays in his private life, namely, that of a father, in order for the addressees to relate to his experiences and thus see him as an in-group member with similar background and set of experiences:

[4] We know about the father who raised two remarkable, caring, beautiful daughters, even after they tried to discourage him from running for President, saying, 'Dad, you're not as cool as you think you are'. (BOC 02 April 2013)

The reporting clause in the FDS is nested in a wider narrative context, in which Obama pictures himself as a loving father who has a strong bond and good rapport with his daughters. As for the cognitive approach (Chilton, 2004, 2005) to examples like extract [4], conceptually there are two independent DSs: one anchored to the speaker (Obama) and another to the PSs (daughters), each with a set of their respective STA coordinates:

Both these spaces are three-dimensional constructs which position discourse entities, for example, actors involved, in (a) the FDS according to a set of STA coordinates and (b) PS's DS along its respective axes (see Table 4). The inclusive person deictic we sets the addressees and the speaker along the A-axis in the FDS enhancing not only their IDC status but also contextual information they share. The NP the father sets the speaker as a representative of a group of parents to whom addressees can relate. What both these DSs share, however, is the A-axis along which in-group members are indicated as belonging and associated, which is further enhanced by axiological coordinates like dad and adjectives remarkable, caring, beautiful relating to the sayers.

In extract [5], stress is put on the speaker's role as the leader reflected in the choice of STA coordinates (see Table 5): 
Table 4. STA coordinates in the speaker's and the sayer's DSs, extract [4].

\begin{tabular}{lll}
\hline & FDS & PS's DS \\
\hline S-axis & $\begin{array}{l}\text { the (father) } \\
\text { present tense in know } \\
\text { Paxis tense in raised, after . . . tried, [were] saying }\end{array}$ & present tense in are, think \\
& $\begin{array}{l}\text { we } \\
\text { (the) father, him } \\
\text { remaxkable, caring, beautiful daughters, they } \\
\text { discourage } \\
\text { President }\end{array}$ & Dad, you \\
& cool
\end{tabular}

STA: spatial, temporal and axiological; FDS: frame discourse space; DS: discourse space; PS: primary sayer.

Table 5. STA coordinates in the speaker's and the sayers' DSs, extract [5].

\begin{tabular}{llll}
\hline & FDS & PSI's DS & PS2's DS \\
\hline S-axis & & shadows (ODC) & the country (I love) \\
T-axis & $\begin{array}{l}\text { past tense in when . . } \\
\text { heard, went, signed up }\end{array}$ & past tense in were going to & present tense in like, love \\
A-axis & $\begin{array}{l}\text { Diegolhe } \\
\text { a chance }\end{array}$ & $\begin{array}{l}\text { we (exclusive of addressees) } \\
\text { offer a chance } \\
\text { (all he) wanted }\end{array}$ & $\begin{array}{l}\text { a normal life } \\
\text { fontribute }\end{array}$ \\
& emerge from shadows & the country I love \\
\hline
\end{tabular}

STA: spatial, temporal and axiological; FDS: frame discourse space; DS: discourse space; ODC: OutsideDeictic-Centre entities; PS: primary sayer.

[5] When Diego heard that (PS1) we were going to offer a chance for folks like him to emerge from the shadows, he went and signed up. (PS2) All he wanted, he said, was a chance to, 'live a normal life' and to 'contribute to the country I love'. (BOC 11 June 2013)

Here, by contrast, the person deictic we is employed as a reference marker exclusive of the addressees. Although they are still conceptualised as IDCs, they are located in the FDS further away from the speaker, who presents himself a political leader wielding power to influence people's lives rather than a regular citizen.

Simultaneously, via the insight into another actor's personal and subjective perspective on a change his policies bring about, he presents himself as a president who takes interest and is acquainted with individuals he has in some way bonded with (first-name reference - Diego). Spatial coordinates are indicated implicitly in FDS and further enhanced in the PS2's DS via NP the country; in the case of PS, however, shadows conceptually locates Diego outside the DC indicating his initial peripheral position and dissociation.

\section{Multilevel representations}

The speaker may embed a number of DSs in his FDS and a number of DSs one within another. In the words of Abbott (2008), '[i]t is not uncommon in narrative to find 
Table 6. STA coordinates in the speaker's and the sayers' DSs, extract [6].

\begin{tabular}{llll}
\hline & FDS & PS's DS & SS's DS \\
\hline $\begin{array}{lll}\text { S-axis } \\
\text { T-axis }\end{array}$ & $\begin{array}{l}\text { before you } \\
\text { past tense in noted } \\
\text { last year }\end{array}$ & past tense in stood and pledge & $\begin{array}{l}\text { (single) out, at the United Nations } \\
\text { auxiliary in will stand up }\end{array}$ \\
A-axis & Rosy & 1 & $\begin{array}{l}\text { the United States } \\
\text { stand up against } \\
\end{array}$ \\
& pledge(d) & $\begin{array}{l}\text { efforts to single out (ODC) } \\
\text { Israel } \\
\text { the United Nations }\end{array}$ \\
\end{tabular}

STA: spatial, temporal and axiological; FDS: frame discourse space; DS: discourse space; ODC: OutsideDeictic-Centre entities; PS: primary sayer; SS: secondary sayer.

embedded narratives within embedded narratives, each serving as a framing narrative for the one nested within it' (p. 29). These representations are strategically employed as means of self-presentation and legitimisation that construct an image of self as an individual whose life experiences and circumstances are relatable to those of the addressees and whom they would thus consider more trustworthy and dependable as a leader who understands them and takes personal interest in their lives. Below are selected extracts indicative of such an image-construction strategy to represent words that have been uttered or written down in the form of letters the speaker received whose content he shares with the audience.

The first of such extracts presents the speaker as a trustworthy leader who keeps promises he has made, thus enhancing his credibility:

[6] As Rosy noted, last year, I stood before you and pledged that, 'the United States will stand up against efforts to single Israel out at the United Nations'. (BOC 04 March 2012)

This narrative representation constitutes an instance of an FDS in which mixedanchorage secondary self-sayer's words are rendered from the primary single-anchorage sayer's perspective, as indicated in Table 6:

The event represented is conceptually located in the FDS according to temporal and axiological coordinates, respectively: via the use of past tense (noted) and an adverbial phrase (last year), as well as via an IDC coordinate Rosie, in which case the first-name reference indicates the actor's close relationship with the speaker and belongingness to the in-group. In the primary DS embedded in the speaker's FDS, the past circumstances in which the secondary self-sayer's utterance was made are plotted in all three dimensions: spatially (before) to indicate physical closeness to the addressees, temporally (via past tense of verbs) to indicate chronology of events and axiologically (I, you, pledge) to communicate rapport and common ground. Finally, in the secondary DS, the axiological dimension is dominant over the remaining two in the sense that IDCs and ODCs are implicitly specified. There is a clear opposition between in-group entities (e.g. the United States and Israel) and efforts made by unnamed entities implicitly known to the addressees who share contextual knowledge with the speaker. Efforts are represented 
Table 7. STA coordinates in the speaker's and the sayers' DSs, extract [7].

\begin{tabular}{|c|c|c|c|c|}
\hline & FDS & PS's DS & SSI's DS & SS2's DS \\
\hline S-axis & $\begin{array}{l}\text { at }(\text { my) desk } \\
\text { the (letters) } \rightarrow a \text { (letter) } \rightarrow \text { this } \\
\text { (letter) }\end{array}$ & & $\begin{array}{l}\text { (all) these (kids) } \\
\text { in this country }\end{array}$ & \\
\hline T-axis & $\begin{array}{l}\text { late last night } \\
\text { past tense in took, read, had } \\
\text { given, got, grew up }\end{array}$ & $\begin{array}{l}\text { a couple of days ago } \\
\text { past tense in asked, } \\
\text { blurted out }\end{array}$ & $\begin{array}{l}\text { present tense in are } \\
\text { future in are going to }\end{array}$ & $\begin{array}{l}\text { past tense } \\
\text { in lost }\end{array}$ \\
\hline A-axis & $\begin{array}{l}\text { I, my (desk), me } \\
\text { my staff } \\
\text { a woman, she } \\
\text { grew up with me }\end{array}$ & $\begin{array}{l}\text { you know } \\
\text { someone } \\
\text { l, me }\end{array}$ & $\begin{array}{l}\text { we } \\
\text { save } \\
\text { kids } \\
\text { in trouble (ODC) }\end{array}$ & $\begin{array}{l}\text { we } \\
\text { lost } \\
\text { them }\end{array}$ \\
\hline
\end{tabular}

STA: spatial, temporal and axiological; FDS: frame discourse space; DS: discourse space; ODC: OutsideDeictic-Centre entities; PS: primary sayer; SS: secondary sayer.

conceptually in terms of a movement (at the United Nations $\rightarrow$ out) and temporal coordinates setting the event in the future by means of the auxiliary will. This representation of a clash the speaker as the leader pledges to prevent is further reinforced axiologically (single out and stand up against), which contributes to the overall construction of an image of a powerful leader.

Extract [7] below adds to his positive image presenting him as a person who maintains close relationships with people from his past and is interested in their lives irrespective of his leadership position. Moreover, this representation provides rationale for and supports the speaker's further claims in the speech with a view to legitimising his stance and political decisions.

[7] Late last night [. . .] I took a little time off at my desk and I read the letters that my staff had given me. And I got a letter from a woman who grew up with me. [. . . In this letter she said, (PS) 'You know, someone asked me a couple of days ago: (SS1) How are we going to save all these kids in this country that are in trouble? I blurted out, (SS2) the same way we lost them'. (BCC 30 April 1993)

The speaker employs a multi-anchored representation of a number of independent sayers: PS (a woman), SS1 (someone) and SS2 (self-sayer I) to render a conversational exchange he learns about from the said letter via reported speech frames.

This instance shows the speaker understands challenges in American educational system, as he has a firsthand account of the situation. As a well-informed leader, he takes up his private time (time off) to take a closer look at problems troubling American citizens. Table 7 clearly indicates contrasting ideas in SS1- and SS2-driven representations on temporal (via tense-driven contrast between the past situation and its present/future solution) and axiological (contrast between save and lost as well as implicitly in vs out of trouble) levels. Moreover, the speaker used spatial proximisation in the FDS introductory narrative - at (my) desk $\rightarrow$ the (letters) $\rightarrow$ a (letter) $\rightarrow$ this (letter), zooming in as if through camera lens to bring the situation more home to the addressees and enable them to conceptually re-live the situation. 
Table 8. STA coordinates in the speaker's and the sayers' DSs, extract [8].

\begin{tabular}{lllll}
\hline & FDS & PS's DS & SSI's DS & SS2's DS \\
\hline S-axis & & other [people] & & \\
T-axis & Past tense in summed & $\begin{array}{l}\text { Present tense in see, } \\
\text { up and said }\end{array}$ & & \\
& say, dream & why & why not \\
A-axis & George Bernard Shaw/he & other people & & \\
& an Irishman & $I$ & & \\
& his approach & things & things that never were & \\
& & &
\end{tabular}

STA: spatial, temporal and axiological; FDS: frame discourse space; DS: discourse space; PS: primary sayer; SS: secondary sayer.

In his address before the Irish Parliament, the speaker aims to convince the Irish to support and join America in their fight against Communism. Setting Ireland and its citizens a model country, the speaker enumerates a number of accomplishments in their struggle for independence and peace. To reinforce the rationale for Irish participation in the worldwide conflict, the speaker refers to the words uttered by one of the greatest Irish playwrights, George Bernard Shaw, endorsing active participation rather than passive observation of events as they happen:

[8] George Bernard Shaw, speaking as an Irishman, summed up an approach to life: Other people, he said "see things and . . say "Why?" . . . But I dream things that never were - $\overline{\text { and I }}$ say: "Why not?", (JKC 28 June 1963)

By selecting this particular utterance, the speaker implies analogy between the approach expressed by George Bernard Shaw and the current situation, in which the Irish are to choose between taking proactive steps and inaction (see Table 8). As for the interplay of DSs, the speaker selected to employ a multi-anchored representation of utterances conceptually tied to PS (Shaw), SS1 (other people) and SS2 (Shaw as a self-sayer).

In the speaker's FDS, the reporting clause is limited to factual information concerning PS and is located along the temporal axis in the past by means of tense-driven coordinates summed up and said and along the axiological axis by means of IDC markers referring to Shaw (he, his approach, an Irishman). His utterance embedded in the FDS via mixed-anchorage representation is a means of elaborating on his approach to life setting apart other people's stance and the one endorsed by PS (I), which is conceptually intensified by yet another stark opposition between the concept of things and things that never were. The axiological dimension also specifies the same clash on yet another level in the SS's DS - a clash between an implicitly proactive why not and passive why. The speaker and other IDCs, including George Bernard Shaw, stand for the same values and attitudes and are represented against ODC's inaction.

In the following extract, the speaker represents a humorous conversation from his experience as the president to picture himself as an approachable, kind and likeable leader one can interact with on a friendly basis: 
Table 9. STA coordinates in the speaker's and the sayers' DSs, extract [9].

\begin{tabular}{|c|c|c|c|c|c|}
\hline & FDS & PS's DS & SSI's DS & SS2's DS & TS's DS \\
\hline S-axis & & here & here & & \\
\hline $\mathrm{T}$-axis & $\begin{array}{l}\text { present tense } \\
\text { in have to }\end{array}$ & $\begin{array}{l}\text { Past tense in met, } \\
\text { was wearing, said }\end{array}$ & $\begin{array}{l}\text { present } \\
\text { tense in is }\end{array}$ & $\begin{array}{l}\text { Present tense in am, } \\
\text { know, are } \\
\text { Past tense in told }\end{array}$ & $\begin{array}{l}\text { past tense } \\
\text { in had to }\end{array}$ \\
\hline A-axis & I & $\begin{array}{l}\text { I } \\
\text { a young corporal, he }\end{array}$ & man & $\begin{array}{l}\text { I, me, my } \\
\text { sorry } \\
\text { sir, my Commander-in-Chief } \\
\text { my grandma }\end{array}$ & I \\
\hline
\end{tabular}

STA: spatial, temporal and axiological; FDS: frame discourse space; DS: discourse space; PS: primary sayer; SS: secondary sayer; TS: tertiary sayer.

[9] Although I have to say (PS) I met a young corporal here who was wearing a black suit. And I said, (SS1) 'Man, it's hot here'. He said, (SS2) 'I'm sorry, sir, I know you're my Commanderin-Chief, but my grandma told me (TS) I had to wear a suit'. (BOC 06 July 2009)

Extract [9] illustrates the use of two PSs whose communicative interaction is rendered through multi-anchorage representations, which creates a vivid representation of a conversation with a young corporal. As can be seen in Table 8 , in the extract in question, the speaker's frame DS holds two separate secondary embedded DSs, one of which holds yet another, tertiary embedded DS within it. Within the PS2's DS another such space is triggered through a single-anchorage representation of a statement made by the corporal's family member, which constitutes both an indication of the value the sayer attached to familial bonds and a sense of respect for the speaker.

\section{Conclusion}

This article aimed to discuss primary and multilevel embedding of distinct DSs one within another as a strategic way of constructing the speaker's image as the leader and an individual the addresses can readily identify with and support as their president, primarily via legitimisation. A vast majority of instances found in the corpus comprise examples of primary representations, in which the sayer's DS is embedded in the FDS. Multiple representations comprise an average of $2 \%$ in all subcorpora probably due to the cognitive cost that is somewhat higher than in the case of primary embedding (see Tversky et al., 1999). PSs are employed as frames for multilevel embedding, mostly by the use of (a) self-sayer (33\% of all cases), namely, reference to the speaker's own words uttered in different spatio-temporal circumstances, and (b) third-party sayers (also 33\%), that is, individuals whose words are rendered via single-anchorage, multi-anchorage or mixed-anchorage representations. Whenever used in non-framing representations that do not have other DS nested in them, the tendency for PSs is virtually the same, with $37 \%$ of self-sayers and $28 \%$ of third-party sayers. This hints at a common pattern for representation of self and legitimisation primarily via these two sayer types. As for the types of 
representations used, in the cases in which primary representations were frames for multiple representations, genuine and illocutionary were far more popular (both occurred in $46 \%$ of cases) than fictive representations, which amounted only to $8 \%$ in all three subcorpora. Non-framing representations are also representative of the same tendency, with $51 \%$ and $36 \%$ of genuine and illocutionary cases, respectively, and $13 \%$ of fictive representations.

Secondary representations employed as frames belong exclusively to the genuine category and are triggered primarily by third-person plural sayers $(80 \%)$ with one instance of a third-party sayer (20\%). As for SSs in general, most common categories included third-party sayer ( $42 \%$ of all cases) and self-sayer $(25 \%)$, other categories ranged from $13 \%$ to $4 \%$ of occurrences only. These speakers were employed primarily in genuine $(63 \%)$ and fictional $(33 \%)$ representations, with very few instances of illocutionary sayers $(4 \%)$, which indicates they were mostly used to represent events which actually took place and narratives that are fictive rather than as frames commenting on the illocutionary force of the reported clauses.

Tertiary representations are rare in the corpus compared to secondary representations. There are five instances of such narrative reports exclusively in BCC and BOC, all of which are genuine and triggered by the use of first-person plural sayers (four instances) and a third-party sayer (one instance). For this reason, quantitative analysis would be inconclusive and no claim other than that there is a potential for TSs to be used as means of self-presentation and legitimisation can be formulated.

\section{Declaration of conflicting interests}

The author(s) declared no potential conflicts of interest with respect to the research, authorship, and/or publication of this article.

\section{Funding}

The author(s) received no financial support for the research, authorship, and/or publication of this article.

\section{Notes}

1. No statistical tests have been performed for this study and no statistical claims made. Occurrences of sayer and representation categories have been taken into consideration to account for consistent patterns of their use across the three subcorpora.

2. In this article, single underline is used to indicate primary sayer's utterance whether it is rendered as a single-anchorage, multi-anchorage or mixed representation, double underline marks the secondary sayer, while wavy underline the tertiary sayer (TS).

\section{References}

Abbott HP (2008) The Cambridge Introduction to Narrative. Cambridge: Cambridge University Press.

Bal M (2009) Narratology: Introduction to the Theory of Narrative. Toronto, ON, Canada: University of Toronto Press.

Bauman R (1986) Story, Performance and Event: Contextual Studies of Oral Narrative. Cambridge: Cambridge University Press. 
Bruner J (1991) The narrative construction of reality. Narrative Inquiry 18(1): 1-21.

Cap P (2006) Legitimisation in Political Discourse: A Cross-Disciplinary Perspective on the Modern US War Rhetoric. Newcastle: Cambridge Scholars Press.

Cap P (2010) Legitimisation in Political Discourse: A Cross-Disciplinary Perspective on the Modern US War Rhetoric. Newcastle: Cambridge Scholars Publishing.

Cap P (2013) Proximization: The Pragmatics of Symbolic Distance Crossing. Amsterdam: John Benjamins.

Cap P (2017) The Language of Fear: Communicating Threat in Public Discourse. Basingstoke: Palgrave.

Chilton PA (2004) Analysing Political Discourse: Theory and Practice. London: Routledge.

Chilton PA (2005) Discourse space theory: Geometry, brain and shifting viewpoints. Annual Review of Cognitive Linguistics 3: 78-116.

Chilton PA (2010) The conceptual structure of deontic meaning: A model based on geometrical principles. Language and Cognition 2(2): 191-220.

Chilton PA (2014) Language, Space and Mind: The Conceptual Geometry of Conceptual Meaning. Cambridge: Cambridge University Press.

Clark HH and Gerrig RJ (1990) Quotations as demonstrations. Language 66(4): 764-805.

Fauconnier G (1985) Mental Spaces. Cambridge, MA: MIT Press.

Fauconnier G (1994) Mental Spaces: Aspects of Meaning Constructions in Natural Language. Cambridge: Cambridge University Press.

Fillmore C (1975) Santa Cruz Lectures on Deixis. Bloomington: Indiana University Linguistics Club.

Frege G (1967 [1892]) The thought: A logical enquiry. In: Strawson PF (ed.) Philosophical Logic. Oxford: Oxford University Press, pp. 17-38.

Gavins J (2007) Text World Theory: An Introduction. Edinburgh: Edinburgh University Press.

Halliday MAK (1981) Explorations in the Function of Language. London: Edward Arnold.

Halliday MAK (1985) An Introduction to Functional Linguistics. London: Edward Arnold.

Hodges A (2011) The 'War on Terror' Narrative: Discourse and Intertextuality in the Construction and Contestation of Sociopolitical Reality. New York: Oxford University Press.

Irvine J (1996) Shadow conversations: The indeterminacy of participant roles. In: Silverstein M and Urban G (eds) Natural Histories of Discourse. Chicago: University of Chicago Press, pp. 131-159.

Levelt WJ (1989) Speaking: From Intention to Articulation. Cambridge, MA: MIT Press.

Levinson S (1983) Pragmatics. Cambridge: Cambridge University Press.

Levinson S (2000) Presumptive Meanings. Cambridge, MA: MIT Press.

Lyons J (1982) Deixis and subjectivity. In: Jarvella R and Klein W (eds) Speech, Place and Action: Studies of Deixis and Related Topics. New York: Wiley, pp. 101-124.

Nunberg G (1998) Indexicality and deixis. In: Kasher A (ed.) Pragmatics: Critical Concepts, Vol III: Indexicals and Reference. London: Routledge, pp. 145-184.

Tannen D (1989) Talking Voices: Repetition, Dialogue, and Imagery in Conversational Discourse. Cambridge: Cambridge University Press.

Tannen D (2006) Intertextuality in interaction: Reframing family arguments in public and private. Text \& Talk 26(4-5): 597-617.

Tversky B, Lee P and Mainwaring S (1999) Why do speakers mix perspectives? Spatial Cognition and Computation 1: 399-412.

Vandelanotte L (2008) Dependency, framing, scope? The syntagmatic structure of sentences of speech or thought representation. Word 59(1): 55-82.

Vandelanotte L (2009) Speech and Thought Representation in English. Berlin: Mouton De Gruyter.

Verschueren J (1999) Understanding Pragmatics. New York: Oxford University Press.

Werth P (1999) Text Worlds: Representing Conceptual Space in Discourse. London: Longman. 


\section{Author biography}

Anna Ewa Wieczorek obtained her PhD in linguistics from the University of Lodz, Poland. Her research interests include pragma-cognitive approach to political discourse analysis, especially proximisation, inclusion and exclusion practices and storytelling techniques involving narrative reports in political speeches. Her most recent book is Clusivity: A New Approach to Association and Dissociation in Political Discourse (2013, Cambridge Scholars). 